\title{
UJI FITOKIMIA DAN UJI TOKSISITAS EKSTRAK DAUN GAMAL (Gliricidia sepium) SEBAGAI INSEKTISIDA NABATI
}

\section{THE PHYTOCHEMICAL TEST AND TOXICITY TEST LEAVES GAMAL (Gliricidia sepium) EXTRACT AS A BOTANICAL INSECTICIDE}

\author{
Ajeng Kartini* , Daniel Tarigandan Chairul Saleh \\ Jurusan Kimia, Fakultas Matematika dan Ilmu Pengetahuan Alam Universitas Mulawarman, Samarinda \\ *Corresponding Author : ajengkartini170@gmail.com
}

Submit : 08 Maret 2017 Accepted : 06 November 2017

\begin{abstract}
Research on phytochemical test and toxicity tests of leaf extract of Gliricidia (Gliricidia sepium) as an insecticide plant have been conducted.. Gliricidia leaves macerated dried samples using ethanol and fractionated using a solvent n-hexane and ethyl acetate. Phytochemical test showed that it contains alkaloids, steroids, triterpenoids, phenolic and flavonoid in total extract. N-hexane fraction containing steroids, triterpenoids and the phenolic. Ethyl acetate fraction containing steroids, triterpenoids, flavonoids, phenolic and saponin. Toxicity test method Brine Shrimp Lethality Test (BSLT) showed that the ethyl acetate fraction had the highest toxicity on shrimp larvae with $\mathrm{LC}_{50}$ values of $49.29 \mathrm{ppm}$. TestActivity as an insecticide plant conducted in animal infestation of rice (Sitophylusorizae Leach) Value $\mathrm{LC}_{50}$ is determined using a regression line between $\log$ concentration and probit mortality, the $\mathrm{LC}_{50}$ obtained is $2.831 \%$. Analysis of the content of chemical compounds in the ethyl acetate fraction from the leaves of Gliricidia produces 9 peak component compounds at mass spectra are shown from the results of GC-MS with 2 peaks compound dominant that serves as an insecticide plant them 2-(3H)-Benzofuranone, 3-methyl and dl-Limonene.
\end{abstract}

Keywords : Gamal (Gliricidia sepium), Phytochemicals,Toxicity,Botanical Insecticide

\section{PENDAHULUAN}

Beras merupakan makanan pokok yang dikonsumsi masyarakat Indonesia. Permasalahan utama yang dapat mengakibatkan penurunan kualitas beras dipenyimpanan hasil pertanian yaitu adanya serangan hama. Hama utama yang menyerang beras didalam penyimpanan yaitu kutu beras (Sitophylus orizae Leach). Serangga Sitophylus oryzae Leach menyebabkan butiran beras menjadi berlobang kecil-kecil serta mudah pecah sehingga kualitasnya rendah. Dimana hama kutu beras dapat menyerang setiap waktu. Kehadiran hama kutu beras ini perlu dikendalikan dengan tepat, agar kualitas dan kuantitas beras dalam simpanan tidak menurun. Salah satu cara pengendalian yaitu dengan menggunakan bahan tanaman sebagai insektisida nabati [1].

Insektisida nabati berasal dari tanaman yang berupa bahan alami yang memenuhi beberapa kreteria seperti: aman, murah, mudah diterapkan dan efektif membunuh hama. Bahan dari tanaman ini juga mudah terurai (Biodegradable) sehingga tidak mencemari lingkungan dan relatif aman bagi manusia dan ternak karena residunya mudah hilang. Salah satu tanaman yang dapat digunakan sebagai insektisida nabati adalah daun gamal (Gliricidia sepium), karena daun dan kulit batang sejak lama sudah dikenal sebagai racun tikus dipusat Amerika dan esktrak gamal juga bersifat anti jamur [2].

Berdasarkan uraian diatas, maka dilakukan penelitian ini untuk mengetahui tentang senyawa metabolit sekunder yang terdapat pada ekstrak total daun gamal (Gliricidia sepium), fraksi etanol, fraksi n-Heksan, dan fraksi etil asetat. Kemudian dari hasil tersebut dilakukan uji toksisitas terhadap larva udang dengan metode Brine Shrimp Lethality Test (BSLT) untuk mengetahui pada fraksi mana yang paling efektif tingkat toksisitasnya. Ekstrak paling toksik dilanjutkan dengan uji karakterisasi GC-MS untuk mengetahui kandungan kimia pada fraksi yang paling aktif, dan dilakukan pengujian untuk mengetahui efektifitasnya terhadap mortalitas hama Kutu beras (Sitophylus oryzae Leach) 
dalam kondisi laboratorium sebagai insektisida nabati.

Dari hasil penelitian ini diharapkan ekstrak daun gamal dapat dijadikan salah satu tumbuhan yang berfungsi sebagai insektisida nabati, sehingga akan menambah nilai guna dari tumbuhan tersebut. Sekaligus dapat memecahkan permasalahan dibidang pertanian khususnya pada hasil panen beras.

\section{METODOLOGI PENELITIAN}

Alat

Adapun alat yang digunakan dalam penelitian ini antara lain Erlenmeyer, corong kaca, gelas kimia, gelas ukur, neraca analitik, seperangkat alat Buchi rotary evaporator, desikator, corong pisah, tabung reaksi, rak tabung reaksi, labu ukur, plat mikro, Tube Lamp (TL), pipet tetes, pipet mikro, hot plate, gunting, batang pengaduk, cawan petri, magnetik stirer ,spatula, jarum, gelas plastik, , tiang statif, gas kromatografi massa spektrometri (GC-MS).

\section{Bahan}

Adapun bahan yang digunakan dalam penelitian ini antara lain daun gamal, etanol, nheksan, etil asetat, aquades, kloroform amoniak, dietil eter, asam sulfat $\left(\mathrm{H}_{2} \mathrm{SO}_{4}\right), \mathrm{CH}_{3} \mathrm{COOH}$ glasial, preaksi dragendrof $\left(\mathrm{Bi}\left(\mathrm{NO}_{3}\right)_{2} .5 \mathrm{H}_{2} \mathrm{O}\right.$, $\mathrm{HNO}_{3}, \mathrm{FeCl}_{3}$, asam klorida, kalium dan serbuk magnesium $(\mathrm{Mg})$, aluminium foil, kertas saring, telur udang (Artemia salina Leach), kutu beras dan beras.

\section{PROSEDUR PENELITIAN Persiapan Sampel}

Sampel daun gamal yang terkumpul dibersihkan dari kotoran yang menempel dan dikeringanginkan pada suhu ruangan sampai sampel benar-benar kering, sampel yang telah kering dipotong menjadi kecil dan dihaluskan .

\section{Ekstraksi Senyawa Metabolit Sekunder}

Ekstraksi senyawa metabolit sekunder dari sampel kering daun gamal dilakukan dengan cara maserasi. Sampel kering yang telah dihaluskan direndam dalam pelarut etanol selama beberapa hari dalam suhu ruang. Maserasi dilakukan secara berulang-ulang hingga larutan ekstrak tidak berwarna lagi. Ekstrak yang diperoleh kemudian disaring dan diuapkan pelarutnya dengan menggunakan rotary evaporator sehingga diperoleh ekstrak total etanol daun gamal.

\section{Fraksinasi}

Ekstrak total etanol daun gamal difraksinasi berdasarkan perbedaan kepolaran pelarut-pelarut organik. Sejumlah ekstrak total daun gamal ditambahkan etanol dan difraksinasi dengan $n$-heksan didalam corong pisah sehingga diperoleh 2 fraksi yaitu fraksi etanol dan fraksi nheksan. Dilakukan penambahan n-heksan berulang kali hingga diperoleh fraksi n-heksan yang jernih. Fraksi n-heksan kemudian dipekatkan dengan menggunakan rotary evaporator dan disebut sebagai ekstrak fraksi nheksan.

Fraksi etanol kemudian difraksinasi dengan penambahan etil asetat. Fraksinasi dilakukan secara berulang hingga diperoleh ekstrak etil asetat yang jernih. Fraksi etil asetat kemudian dipekatkan menggunakan rotary evaporator dan disebut sebagai fraksi etil asetat.

\section{Uji Fitokimia \\ Uji Alkaloid}

Uji Alkaloid dilakukan dengan preaksi Dragendorff (Kalium tetraiodobismutat). Sejumlah ekstrak total dan masing-masing fraksi dilarutkan dengan pelarut yang sesuai. Larutan ekstrak sebanyak $1 \mathrm{~mL}$ kemudian ditambahkan dengan 5 tetes asam sulfat $2 \mathrm{~N}$ dan didiamkan beberapa saat. Larutan kemudian ditambahkan dengan 3 tetes preaksi dragendorff. Adanya alkaloid ditunjukan dengan terbentuknya endapan jingga sampai merah coklat pada pereaksi dragendroff [3].

\section{Uji Saponin ( Uji Forth)}

Sejumlah ekstrak total dan masing-masing fraksi dilarutkan dalam $2 \mathrm{~mL}$ aquades kemudian dikocok kuat tabung reaksi, jika timbul busa ditambah 1 tetes $\mathrm{HCl}$ pekat. Ekstrak positif mengandung saponin apabila terdapat busa dengan ketinggin 1-3 $\mathrm{cm}$ bertahan selama 15 menit [4].

\section{Uji Steroid dan Triterpenoid/ Uji Libermann- burchard}

Uji steroid dan triterpenoid dilakukan dengan perekasi Lieberman Burchard (Asam asetat glasial dan asam sulfat pekat 10:1) sejumlah ekstrak total dan masing-masing fraksi dilarutkan dalam pelarut yang sesuai. Larutan ekstrak sebanyak $1 \mathrm{~mL}$ ditambahkan dengan 10 tetes asam asetat glasial. Larutan dikocok perlahan dan dibiarkan selama beberapa menit kemudian ditambahkan dengan 2-3 tetes asam sulfat pekat. adanya Steroid memberikan warna biru atau hijau, sedangkan untuk triterpenoid memberikan warna merah atau ungu. 


\section{Uji Flavonoid}

Uji Flavonoid dilakukan dengan metode wilstater. Sejumlah ekstrak total dan masingmasing fraksi dilarutkan dengan pelarut yang sesuai. Larutan ekstrak sebanyak $1 \mathrm{~mL}$ kemudian ditambahkan sedikit serbuk Mg dan 3 tetes HCL pekat. Uji positif ditunjukan dengan terbentuknya warna merah, kuning atau jingga

\section{Uji Fenolik}

Sejumlah ekstrak total dilarutkan dan masing-masing fraksi dilarutkan dalam pelarut yang sesuai. Larutan ekstrak sebanyak $1 \mathrm{~mL}$ ditambahkan dengan 3 tetes $\mathrm{FeCl}_{3} 1 \%$. Ekstrak positif menghasilkan warna hijau, merah, ungu, biru atau hitam pekat.

\section{Uji toksisitas Larva Udang Metode BSLT (Brine Shrimp Lethality Test)}

Pengujian toksisitas dilakukan terhadap ekstrak n-Heksan, etil asetat dan ekstrak kasar etanol.

\section{Penetasan telur Artemia salina Leach}

Sebuah kompartemen yang terdiri dari dua bagian yang dipisahkan dengan sekat berlubang disiapkan untuk pembiakan larva udang. Sebanyak $10 \mathrm{mg}$ telur udang Artemia salina Leach ditambahkan $100 \mathrm{~mL}$ air laut yang telah disaring dan dimasukan ke dalam kompartemen yang gelap sedangkan kompertemen lainnya diberi pencahayaan lampu teflon agar menetas sempurna. Setelah 48 jam telur udang menetas dan siap diuji cobakan [5].

\section{Pembuatan Larutan Sampel 1000 ppm}

Sebanyak $1 \mathrm{mg}$ sampel dilarutkan dalam $100 \mu \mathrm{L}$ DMSO dan diencerkan dengan $900 \mu \mathrm{L}$ air laut sehingga diperoleh konsentrasi 1000 ppm.

\section{Pembuatan Larutan Kontrol}

Larutan kontrol dibuat sama dengan prosedur diatas tanpa menggunakan sampel.

\section{Prosedur Uji Metode Meyer}

Sebuah 2 buah plat mikro standar disiapkan masing-masing untuk plat uji dan plat kontrol. Baris I dan II masing-masing 3 kolom dimasukan $100 \mu \mathrm{L}$ sampel $1000 \mathrm{ppm}$ pada plat uji dan $100 \mu \mathrm{L}$ larutan kontrol pada plat kontrol. Larutan baris II pada plat uji diencerkan dengan $100 \mu \mathrm{L}$ air laut dan diaduk. Kemudian dipipet kembali $100 \mu \mathrm{L}$ larutan baris II dan dimasukan kedalam baris III. Larutan baris III diencerkan kembali dengan $100 \mu \mathrm{L}$ air laut sambil diaduk dan dimasukan kedalam baris selanjutnya. Seterusnya dilakukan hal yang sama sampai baris terakhir sehingga diperoleh konsentrasi larutan pada masing-masing baris plat uji sebagai berikut: baris I $=1000 \mathrm{ppm}$, baris II $=500 \mathrm{ppm}$, baris III $=250 \mathrm{ppm}$, baris IV $=125 \mathrm{ppm}$, baris V $=62,5 \mathrm{ppm}$, baris $\mathrm{VI}=31,2 \mathrm{ppm}$, baris VII $=$ $15,6 \mathrm{ppm}$, baris VIII $=7,8 \mathrm{ppm}$.

Selanjutnya kedalam larutan sampel pada plat uji dan larutan kontrol pada plat kontrol ditambahkan $100 \mu \mathrm{L}$ air laut yang mengandung 8-15 larva udang dan dibiarkan selama 24 jam. Jumlah larva udang yang mati dan hidup pada setiap baris plat uji dihitung setelah 24 jam dan nilai $\mathrm{LC}_{50}$ ditentukan dengan uji probit menggunakan SAS (Statistical Analisis System).

\section{Analisis Senyawa Ekstrak Daun Gamal dengan GC-MS}

Sampel ekstrak daun gamal fraksi etil asetat dianalisis dengan Kromatografi Gasspektrometri massa untuk mengetahui kandungan kimia yang terdapat pada sampel.

\section{Pengujian Ekstrak Daun Gamal terhadap kutu beras (Sitophylus Oryzae Leach) Penyiapan Bioindikator}

Terlebih dahulu disiapkan kutu beras yang akan digunakan, kutu beras didapatkan dari tempat penyimpanan beras yang sudah berkutu kemudian dilakukan pemilihan kutu beras secara visual untuk kutu beras yang diujikan.

\section{Uji Mortalitas kutu beras}

Ekstrak daun gamal fraksi etil asetat dibuat beberapa konsentrasi yaitu $1,5 \%, 2 \%, 2,5 \%$ dan $3 \%$. Ditimbang masing-masing beras (makanan kutu beras) seberat \pm 25 gram, beras direndam pada masing-masing konsentrasi ekstrak \pm 10 menit kemudian dikering anginkan pada suhu ruang. Sebagai kontrol digunakan beras yang tidak diberi ekstrak tetapi hanya diberi aquadest (perlakuan dengan konsentrasi $(0 \%)$, kemudian beras yang telah mengandung ekstrak tersebut dimasukan kedalam bejana uji lalu dimasukan 10 ekor kutu beras. Bejana uji yang telah berisi kutu beras ditutup dengan aluminium lalu ditusuktusuk dengan jarum agar udara dapat masuk. Setiap konsentrasi perlakuan dilakukan pengulangan masing-masing tiga kali.

Parameter yang diamati adalah jumlah kutu yang mati selama 72 jam pada masingmasing unit perlakuan dan dihitung jumlah akumulatifnya.Data mortalitas kutu beras selama 72 jam ditulis ke dalam tabel pengamatan, sedangkan hasil isolasi diuraikan secara deskriptif. Nilai dugaan $50 \%$ konsentrasi $\left(\mathrm{LC}_{50}\right)$ ditentukan dengan menggunakan persamaan garis 
regresi antara log konsentrasi dan probit kematian (probit analisis).

\section{HASIL DAN PEMBAHASAN \\ Hasil Ekstraksi}

Sampel yang digunakan pada penelitian ini adalah daun gamal (Gliricidia sepium). Tumbuhan ini diperoleh dari Handil Kecamatan Muara Jawa, Kabupaten Kutai Kartenegara dan telah dideterminasi di Laboratorium Sistematika dan Anatomi Tumbuhan FMIPA. Adapun berat ekstrak dan masing-masing fraksi disajikan dalam tabel berikut ini:

Tabel 1. Ekstrak Hasil Ekstraksi Daun Gamal.

\begin{tabular}{lc}
\hline \multicolumn{1}{c}{ Jenis Ekstrak } & $\begin{array}{c}\text { Massa } \\
\text { (Gram) }\end{array}$ \\
\hline Ekstrak kasar Etanol & 50,25 \\
$\begin{array}{l}\text { Ekstrak Pekat Fraksi } n \text { - } \\
\text { heksana }\end{array}$ & 7,80 \\
$\begin{array}{l}\text { Ekstrak Pekat Fraksi etil } \\
\text { asetat }\end{array}$ & 17,54 \\
\hline
\end{tabular}

\section{Skrining Fitokimia}

Berdasarkan hasil uji fitokimia terhadap ekstrak kasar etanol, ekstrak fraksi $n$-heksana dan ekstrak fraksi etil asetat dari daun gamal (Gliricidia sepium) terlihat kandungan metabolit sekundernya seperti yang ditunjukkan pada Tabel 2.

Tabel 2. Hasil Uji Fitokimia dari Ekstrak Kasar Etanol, Ekstrak Pekat Fraksi $n$-heksana dan Ekstrak Pekat Fraksi Etil Asetat daun gamal (Gliricidia sepium)

\begin{tabular}{lccc}
\hline & \multicolumn{3}{c}{ Jenis Ekstrak } \\
\cline { 2 - 4 } Jenis & $\begin{array}{c}\text { Ekstrak } \\
\text { Kasar } \\
\text { Etanol }\end{array}$ & $\begin{array}{c}\text { Ekstrak } \\
\text { Fraksi n- } \\
\text { Heksan }\end{array}$ & $\begin{array}{c}\text { Ekstrak } \\
\text { Fraksi } \\
\text { Etil } \\
\text { Asetat }\end{array}$ \\
\hline Alkaloid & + & - & - \\
Saponin & - & - & + \\
Steroid & - & + & + \\
Triterpenoid & + & + & + \\
Flavonoid & + & - & + \\
Fenolik & + & + & + \\
\hline
\end{tabular}

Keterangan :

$(+)=$ mengandung senyawa metabolit sekunder

$(-)$ = tidak mengandung senyawa metabolit sekunder

\section{Uji Toksisitas (BSLT)}

Berdasarkan perhitungan dengan Analisis probit SAS terhadap ekstrak kasar Etanol, Fraksi $n$-heksan, fraksi etil asetat daun gamal (Gliricidia sepium) diperoleh $\mathrm{LC}_{50}$ (Lethal Concentration $50 \%$ ), diperlihatkan pada tabel 3.

Tabel 3. Nilai $\mathrm{LC}_{50}$ Uji Mortalitas Larva Udang pada Ekstrak Kasar Etanol, Ekstrak fraksi $n$-heksan dan Ektrak Fraksi Etil asetat daun gamal (Gliricidia sepium).

\begin{tabular}{clc}
\hline No & \multicolumn{1}{c}{ Jenis Ekstrak } & $\begin{array}{c}\mathbf{L C}_{\mathbf{5 0}} \\
(\mathbf{p p m})\end{array}$ \\
\hline 1 & Ekstrak kasar Etanol & 61,31 \\
2 & $\begin{array}{l}\text { Ekstrak Pekat Fraksi } n \text { - } \\
\text { heksana }\end{array}$ & 66,48 \\
3 & $\begin{array}{l}\text { Ekstrak Pekat Fraksi etil } \\
\text { asetat }\end{array}$ & 49,29 \\
\hline
\end{tabular}

Berdasarkan data diatas menunjukan bahwa ekstrak fraksi etil asetat memiliki bioaktivitas paling tinggi terhadap larva udang, yang ditunjukan dengan nilai $\mathrm{LC}_{50}$ yang paling kecil yaitu 49,29 ppm. Nilai ini menunjukan bahwa pada konsentrasi tersebut, ekstrak sampel mampu membunuh larva udang sampai $50 \%$ populasi.

\section{Analisis GC-MS Fraksi Etil Asetat Daun Gamal}

Analisa senyawa pada fraksi etil asetat daun gamal menggunakan GC-MS dilakukan untuk mengetahui komposisi dan berat molekul dari fraksi etil asetat tersebut, diperoleh informasi komponen senyawa kimia pada fraksi etil asetat daun gamal sebanyak 9 senyawa, dari 9 senyawa tersebut terdapat 2 senyawa dominan yang mempunyai aktivitas sebagai Insektisida nabati menurut literatur yaitu 2(3H)-Benzofuranone, 3metil (CAS) dan dl-limonena dengan masingmasing persen area sebesar 43,035\% dan 16,33\% dapat dilihat pada Tabel 4.

Tabel 4. Hasil Analisis GC-MS Fraksi Etil Asetat Daun Gamal

\begin{tabular}{cccc}
\hline Peak & $\begin{array}{c}\text { Waktu } \\
\text { Retensi }\end{array}$ & $\begin{array}{c}\% \\
\text { total }\end{array}$ & NamaSenyawa \\
\hline
\end{tabular}




\begin{tabular}{cccl}
\hline 1 & 2,550 & 16,33 & $\begin{array}{l}\text { Asam propanoat, } \\
\text { etil ester (CAS) } \\
\text { metil laurat }\end{array}$ \\
2 & 4,353 & 0,544 & Xylene \\
3 & 4,466 & 2,629 & $\begin{array}{l}\text { Benzene, 1,3- } \\
\text { dimetil }\end{array}$ \\
4 & 4,841 & 0,897 & dl-limonena \\
5 & 7,079 & 19,895 & linalool L \\
6 & 8,193 & 6,028 & z-cintral \\
7 & 10,327 & 3,819 & z-cintral \\
8 & 10,745 & 6,823 & $\begin{array}{l}\text { (3H) } \\
\text { Benzofuranone, 3 } \\
\text { metil (CAS) }\end{array}$ \\
\hline
\end{tabular}

Berikut adalah hasil spectra massa analisa GCMS dari fraksi etil asetat daun gamal (Gliricidia sepium)

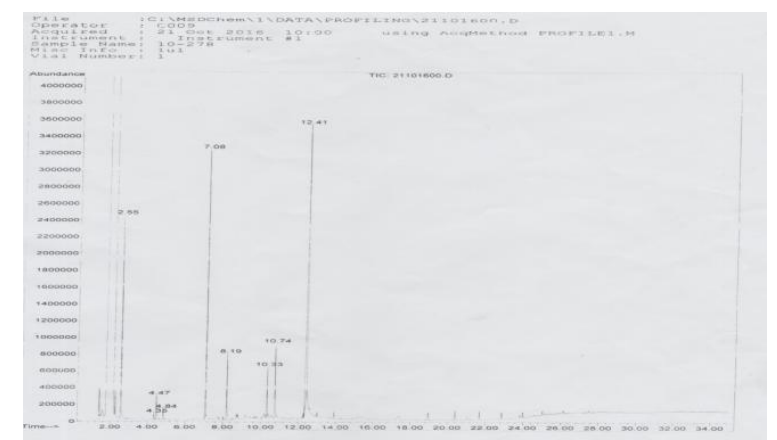

Gambar 1. Spektrum Massa dari fraksi etil asetat daun gamal (Gliricidia sepium)

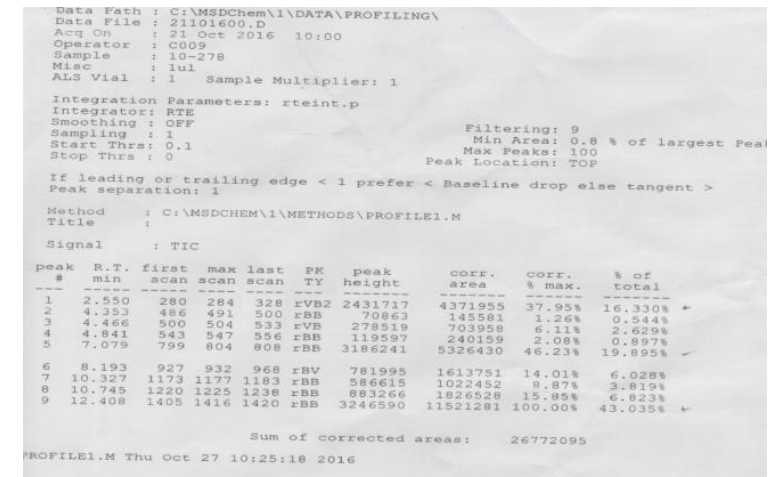

Gambar 2. Spektrum Massa dari fraksi etil asetat daun gamal (Gliricidia sepium)

Berikut adalah spektra massa $2(3 \mathrm{H})$ Benzofuranone, 3-metil- (CAS) yang memiliki waktu retensi sebesar 12.408, presentase sebesar 43,035\% memiliki berat molekul 148 dengan rumus $\mathrm{C}_{9} \mathrm{H}_{8} \mathrm{O}_{2}$.

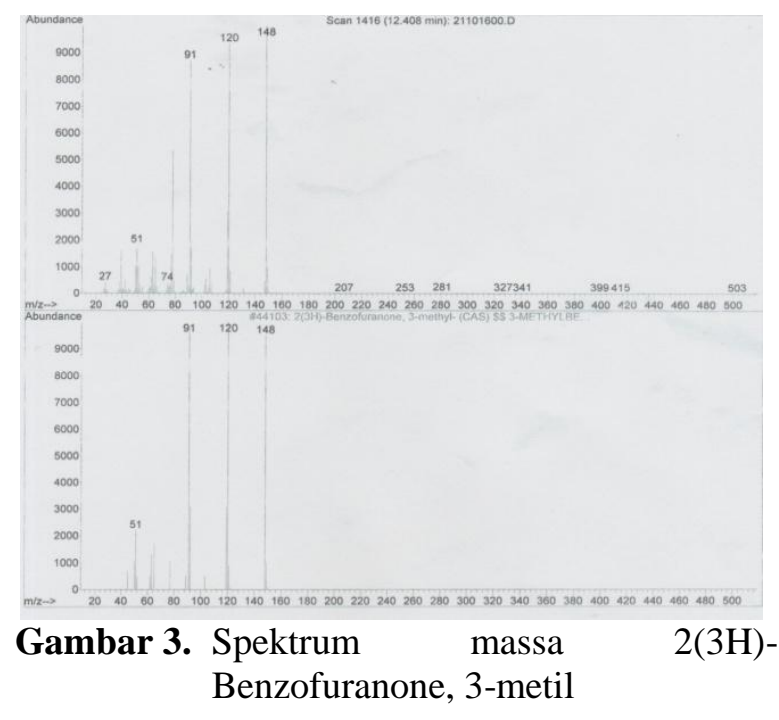

Pola fragmentasi dari senyawa 2(3H)Benzofuranone, 3-metil (CAS) dapat digambarkan sebagai berikut:

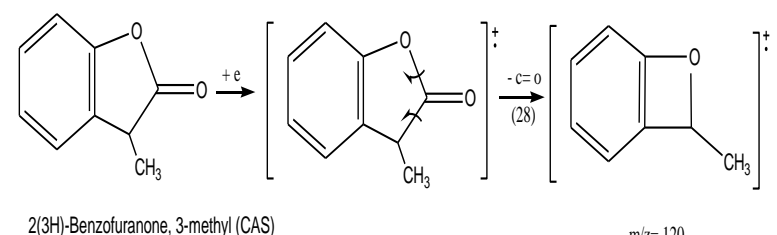

Gambar 4. Pola Fragmentasi senyawa 2(3H)Benzofuranone, 3-metil (CAS)

Spektra Massa berikutnya adalah spektrum massa dl-Limonena yang memiliki waktu retensi sebesar 7.079 dan presentase sebesar $19.895 \%$. Senyawa dl-Limonena memiliki berat molekul 136 dengan rumus $\mathrm{C}_{10} \mathrm{H}_{16}$.

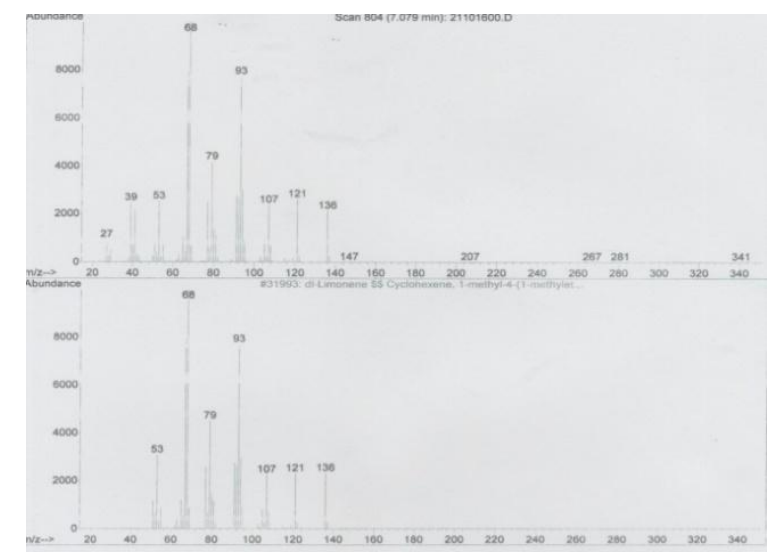

Gambar 5. Spektrum massa dl-limonena

Pola fragmentasi dari senyawa dl-limonena dapat digambarkan sebagai berikut: [6]. 


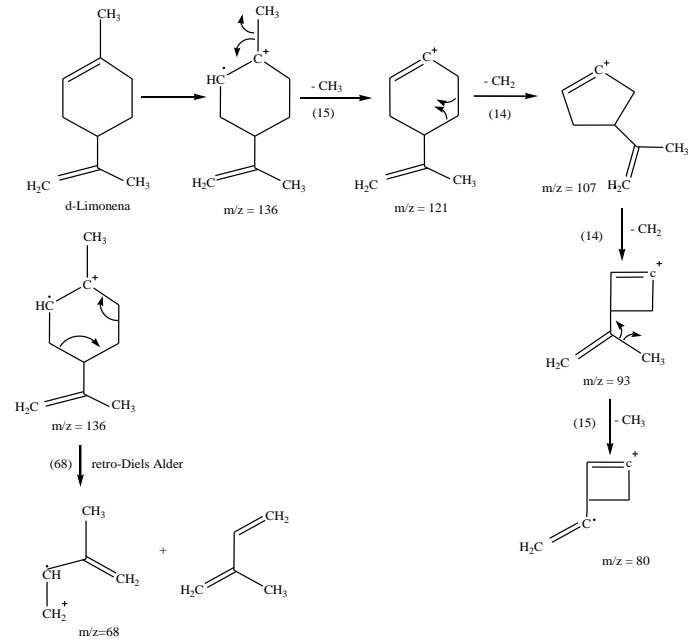

Gambar 6. Pola Fragmentasi senyawa dl limonena

Senyawa 2(3H)- Benzofuranone, 3-metil dan dl-limonena menurut literatur yang diperoleh senyawa tersebut memiliki potensi sebagai insektisida nabati. Penelitian yang telah dilakukan mengisolasi dan mengidentifikasi beberapa turunan senyawa benzofuran dari tanaman A.odorata memiliki toksisitas yang kuat terhadap larva spodoptera littoralis. Wibaldus menginformasikan senyawa dl-limonena dari minyak atsiri jeruk nipis menyebabkan mortalitas rayap dan dapat merusak sistem syaraf pada rayap. Kedua literatur tersebut membuktikan bahwa senyawa $2(3 \mathrm{H})$ - Benzofuranone, 3-metil dan dl-limonena berpotensi sebagai insektisida nabati.

\section{Hasil Uji Insektisida Nabati Ekstrak EtilAsetat Daun Gamal Terhadap Kutu Beras} Insektisida nabati yang berasal dari ekstrak fraksi etil asetat daun gamal. Hasil pengamatan uji Insektisida nabati terhadap kutu beras pada berbagai konsentrasi diperoleh data yang ditunjukkan pada Tabel 5 berikut:

Tabel 5. Hasil Uji Mortalitas Kutu Beras

\begin{tabular}{|c|c|c|c|c|c|c|c|}
\hline \multirow{2}{*}{ No } & \multirow{2}{*}{$\begin{array}{c}\text { Konsentrasi } \\
\quad(\%)\end{array}$} & \multirow{2}{*}{$\begin{array}{c}\text { Jumlah } \\
\text { Hewan Uji }\end{array}$} & \multicolumn{3}{|c|}{$\begin{array}{c}\text { Jumlah Hewan Uji } \\
\text { yang Mati }\end{array}$} & \multirow{2}{*}{$\begin{array}{l}\text { Rata-rata } \\
\text { Mortalitas }\end{array}$} & \multirow{2}{*}{$\begin{array}{c}\text { Persentase } \\
\text { Mortalitas } \\
\quad(\%)\end{array}$} \\
\hline & & & U1 & $\mathbf{U} 2$ & U3 & & \\
\hline 1 & Kontrol & 10 & 0 & 0 & 0 & 0 & 0 \\
\hline 2 & 1,5 & 10 & 1 & 2 & 2 & 1,66 & 16,6 \\
\hline 3 & 2,0 & 10 & 4 & 3 & 3 & 3,33 & 33,3 \\
\hline 4 & 2,5 & 10 & 4 & 5 & 5 & 4,66 & 46,6 \\
\hline 5 & 3,0 & 10 & 7 & 6 & 8 & 7 & 70 \\
\hline \multicolumn{4}{|c|}{$\begin{array}{l}\text { i konsentrasi ekstrak daun gamal fraksi } \\
\text { dan mortalitas kutu beras pada Tabel } \\
\text { ntrasi diubah dalam bentuk Xi (log } \\
\text { asi x 100) dan mortalitas kutu beras } \\
\text { p ulangan dalam bentuk skala probit } \\
\text { elihat hasil LC } \text { S0. Log konsentrasi }_{50} \\
\text { kurva hubungan konsentrasi ekstrak } \\
\text { nal fraksi etil asetat dengan probit } \\
\text { kutu beras. Grafik tersebut dapat } \\
\text { da Gambar } 7 \text {. }\end{array}$} & & 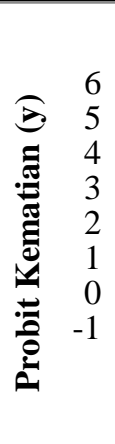 & Log Kon & 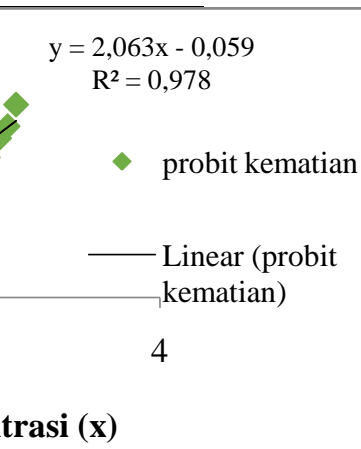 \\
\hline
\end{tabular}

Gambar 7. Persamaan Probit Kematian

Berdasarkan analisis regresi antara log konsentrasi ekstrak dengan probit kematian hewan uji diperoleh persamaan regresi linier $\mathrm{Yi}=$ $2.063 \mathrm{x}-0.059$ dengan nilai korelasi $\mathrm{R}^{2}=$ 
0.978 pada garis regresinya menunjukan garis lurus, maka diperoleh nilai toksisitas $\mathrm{LC}_{50}$ sebesar 2,831\% diartikan bahwa pada konsentrasi tersebut terjadi kematian sebanyak $50 \%$ dari hewan uji selama 72 jam.

Metode pengujian insektisida nabati dilakukan dengan metode pencampuran makanan. Ekstrak fraksi etil asetat daun gamal dicampurkan dengan beras sebagai sumber makanan Sitophylus orizae . Ekstrak daun gamal diduga bersifat racun perut dan racun pernapasan terhadap Sitophylus orizae, dimana pada seranggga yang telah diberi perlakukan ekstrak daun gamal menunjukan gejala awal yaitu serangga bergerak naik kealuminium foil penutup bejana uji. Hal ini membuktikan bahwa bahan aktif dalam ekstrak daun gamal fraksi etil asetat mengganggu pernapasan serangga dengan adanya peningkatan $\mathrm{CO}_{2}$ melebihi konsentrasi $\mathrm{O}_{2}$ sehingga serangga bergerak mencari udara segar. Konsentrasi $\mathrm{O}_{2}$ yang rendah menyebabkan spirakel serangga terus membuka dan menyebabkan kematian. Beberapa serangga uji yang mati dalam posisi terbalik, hal ini karena terjatuh dari penutup dan tidak mampu membalikan tubuh keposisi kedaaan sebenarnya [7].

\section{KESIMPULAN}

Berdasarkan penelitian yang telah dilakukan diketahui jenis metabolit sekunder yang terkandung pada ekstrak kasar etanol mengandung senyawa alkaloid, triterpenoid, fenolik dan flavonoid; Ekstrak fraksi n-heksan mengandung senyawa steroid, triterpenoid dan fenolik. Ekstrak fraksi etil asetat mengandung senyawa steroid, triterpenoid, flavonoid, fenolik dan saponin. Berdasarkan hasil uji $\mathrm{LC}_{50}$ mortalitas larva udang (BSLT) didapatkan nilai $\mathrm{LC}_{50}$ pada ekstrak kasar etanol yaitu 61,31 ppm, pada fraksi n-heksan yaitu 66,48 ppm, pada freaksi etil asetat 49,29 ppm dimana fraksi etil asetat memiliki toksisitas yang paling tinggi Berdasarkan hasil uji toksisitas terhadap kutu beras ekstrak fraksi etil asetat daun gamal didapatkan nilai $\mathrm{LC}_{50}$ yaitu $2,831 \%$ diartikan bahwa pada konsentrasi tersebut terjadi kematian sebanyak $50 \%$ dari hewan uji selama 72 jam. Hasil identifikasi kandungan kimia dengan GCMS dari daun gamal fraksi etil asetat didapatkan 2 senyawa yang paling dominan yang berfungsi sebagai insektisida nabati yaitu diduga senyawa 2 (3H)- Benzofuranone, 3-metil- (CAS) dan dlLimonena.

\section{DAFTAR PUSTAKA}

[1] Benny. 2016. Uji Dosis Tepung Buah Sirih Hutan (Piper aduncum L) Terhadap Mortalitas Hama Sitophilus oryzae L, Pada Beras Dipenyimpanan. Jorn Faperta Vol 3 No 1 Februari 2016. Universitas Riau.

[2] Nismah, Utami dan Pratami, D.G. 2011. Isolasi Senyawa Flavonoid dari Ekstrak Serbuk Daun Gamal (Gliricidia sepium) dan Uji Toksisitasnya Terhadap Hama Kutu Putih Pepaya (Paracoccus marginatus). Laporan Penelitian Fakultas MIPA, Universitas Lampung.

[3] Robinson. 1995. Kandungan Kimia Organik Tumbuhan Tinggi. Bandung : Penerbit ITB.

[4] Harborne, J. B. 1987. Metode Fitokimia: Penentuan Cara Modern Menganalisis Tumbuhan. Bandung: Penerbit ITB.

[5] Kadarisman, I. 2000. "Isolasi dan Indentifikasi Senyawa Kimia Bioaktif dari Rimpang Bangle (Zingiber cassumunar Roxb)". Skripsi Jurusan Kimia FMIPA, Institut Pertanian Bogor.

[6] Wibaldus. 2016. Bioaktivitas Minyak Atsiri Kulit Buah Jeruk Nipis (Citrus aurantifolia) Terhadap Rayap Tanah (Coptotermes sp.). Program Studi Kimia Fakultas Matematika dan Ilmu Pengetahuan Alam Universitas Tanjung Pura.

[7] Novizan. 2002. Membuat dan Memanfaatkan Pestisida Ramah Lingkungan. Jakarta: PT. Agromedia Pustaka. 